\title{
Comparative study of carbamazepine and sodium valproate on - free triiodothyronine, in paediatric patients in teaching hospital
}

\author{
Gupta D. ${ }^{1}$, Kumar A. ${ }^{2}$ \\ ${ }^{1}$ Dr. Dharmender Gupta, Associate Professor, Department of Pharmacology, Varun Arjun Medical College and \\ Rohilkhand Hospital, Banthra, Shahjahanpur, Uttar Pradesh, ${ }^{2}$ Dr. Atul Kumar, Assistant Professor, Department of \\ Paediatrics, Shri Ram Murti Smarak Institute of Medical Sciences, Bareilly, Uttar Pradesh, India.
}

Corresponding Author: Dr Atul Kumar, Assistant Professor, Department of Paediatrics, Shri Ram Murti Smarak Institute of Medical Sciences, Bareilly, Uttar Pradesh, India. E-mail: atulkgmu@gmail.com

\begin{abstract}
Background: This study was conducted in Department of Paediatrics, Sanjay Gandhi Memorial Hospital, Mangolpuri, Delhi 83. Objective of the study was to measure and compare TSH, FT4, FT3, hormone level before, after 3 month and 6 months after starting Carbamazepine and Sodium Valproate monotherapy in 2-12 years old children. Method: This prospective study performed in 82 newly diagnosed Paediatric patients with partial/ generalized seizures, subdivided into two groups: 42 patients treated with carbamazepine and 40 patients treated with valproic acid. 30 age and sex matched subjects served as controls. Free triidothyronine (FT3) evaluated at baseline and at $3^{\text {rd }}$ and $6^{\text {th }}$ months in all patients and in control group. Height, weight, BMI and liver function test were also evaluated at baseline at $3^{\text {rd }}$ and $6^{\text {th }}$ months in all patients and in control group. Results: At baseline thyroid function was normal in all epileptic patients in controls. Decrease in mean FT3 level (from $5.57 \pm 0.90 \mathrm{pmol} / 1$ at baseline, $5.51 \pm 0.75 \mathrm{pmol} / 1$ after 3 months and $5.13 \pm 0.78 \mathrm{pmol} / 1$ after 6 months of therapy) was seen in CBZ group even though that was not significant ( $p=0.434$ at 3 months, $p=0.372$ at 6 months). In VPA treated patients there was no statistically significant difference found in FT3level after 3 and 6 months of therapy. Conclusion: Our data suggest that VPA monotherapy does not alter FT3 level. On the contrary alterations of thyroid hormones occur in CBZ treated children, however the patients remained euthyroid.
\end{abstract}

Keywords: Comparative study, carbamazepine, sodium valproate, triiodothyronine, Paediatrics

\section{Introduction}

Epilepsy is the commonest neurological turmoil which knows no racial, geological, and social limits. A Seizure is a transient event of signs as well as side effects coming about because of extreme or synchronous movement in the brain

The International Classification of Epileptic seizures isolate epileptic seizures into two vast classes.

- Focal (Partial) - in Focal seizures, the primary clinical and EEG changes propose beginning actuation of neurons constrained to part of one cerebral side of the equator.

- Generalized seizures - the principal clinical and EEG changes show synchronous association of both side of the equator.

Manuscript received: $30^{\text {th }}$ August 2019

Reviewed: $10^{\text {th }}$ September 2019

Author Corrected: $18^{\text {th }}$ September 2019

Accepted for Publication: $23^{\text {rd }}$ September 2019
Epilepsy is a disorder of the cerebrum described by a suffering inclination to produce seizures and by the neurobiological, subjective, mental and social outcomes of this condition. The clinical analysis of the epilepsy for the most part requires the event of no less than one unmerited epileptic seizure with either second such seizure or enough EEG and clinical data to convincingly exhibit and suffering inclination to create repeats [1]. For epidemiologic purposes epilepsy is viewed as present when at least two unwarranted seizure happen in a time period of $>24$ hours.

There are numerous medications utilized for treatment of epilepsy. Most usually utilized antiepileptic drugs are Carbamazepine and Valproic acid. Metabolic symptoms of antiepileptic prescription have been the reason for concern. Regardless of whether these medications require customary observing and mediation to amend the unhinged metabolic marker is broadly debated. The

Pediatric Review: International Journal of Pediatric Research Available online at: www.medresearch.in 460|P a g e 


\section{Original Research Article}

first investigation about the impact of antiepileptic sedates on thyroid organ was made in Oppenheimer et al in 1961, they found a reduction in iodine official to serum protein and an aggravation in thyroxin discharge from thyroxin restricting globulin [2]. Antiepileptic drugs with chemical instigating properties, for example, Carbamazepine, Phenytoin ordinarily actuate decreased dimension of thyroxin and free thyroxin yet have transient impact on dimension of TSH [3].

Carbamazepine is the most broadly utilized first line Antiepileptic drugs in partial epilepsy of the adults and kids. Carbamazepine treatment has certain impact on thyroid capacity it declines the serum thyroid hormone level however permits the serum Thyrotropin fixation and TSH reaction to TRH stays typical. It has been conjectured that these low serum TSH level are because of acceptance of hepatic p450 chemical framework via Carbamazepine [3].

Valproic acid is broadly utilized for treatment of both Partial and Generalized epilepsy in childhood. The impacts of Valproic acid on thyroid hormones balance are clashing as both low and typical serum Thyroxin and free Thyroxin level have been found in patient accepting Valproic acid monotherapy however never connected with unmistakable thyroid brokenness [4]. A few investigations show ordinary mean TSH level while different examinations recorded high TSH level in patient accepting Valproate treatment [5].

\section{Methods and Material}

Type of Study -This was a prospective study conducted in Department of Paediatrics, of Sanjay Gandhi Memorial Hospital, Mangolpuri, Delhi in collaboration with Department of Pathology of same institute.

Ethical committee clearance - This study was done after obtaining proper permission from institutional ethical committee

Sampling Method: Random sampling was used. Total 132 children were enrolled in study out of which 98 children were presented with partial/ generalized seizure out of these 98 children, 50 children received carbamazepine, 48 children received valproic acid. 34 children were age and sex matched controls admitted in Department of Paediatrics for diseases other than seizure. Considering 30\% lost to follow up the children in the age group of 2-12 years presenting with partial seizures / generalized seizures were randomly enrolled in the study and were followed for six months.
With the effect size of 0.50 at two tailed alpha value $(0.05)$, beta value $(0.2)$ and $95 \%$ confidence interval and $80 \%$ power of study, 90 observations (30 per group) would be sufficient to detect a significant difference in FT3 at 3 months and 6 months between any of two groups.

\section{Inclusion criteria}

- Children in the age group of 2-12 years presenting with $\mathrm{partial} /$ generalized seizures.

- Children who have not received any Antiepileptic therapy.

\section{Exclusion criteria}

- Children who had received any anticonvulsant before Carbamazepine/Valproic acid therapy.

- Taking any medication known to alter thyroid function.

- Children with any chronic liver/kidney disease.

- Children with developmental delay/ any major congenital anomaly.

Total 132 children were enrolled in study out of which 98 children were presented with partial/ generalized seizure out of these 98 children, 50 children received carbamazepine, 48 children received valproic acid. 34 children were age and sex matched controls admitted in Department of Pediatrics for diseases other than seizure.

Seizure was classified according to the recommendation of International League of Epilepsy. Carbamazepine was used particularly with partial seizures with or without generalization and valproic was used primarily for patients with primary generalized seizures.

After obtaining written consent, detailed history of previous drug intake especially that can alter thyroid function, history suggestive of chronic liver or chronic kidney disease. Relevant family history was also been taken and was recorded in case record form. Third group was of age and sex matched children admitted in Department of Paediatrics for diseases other than seizure. Weight, Height, BMI, LFT, KFT was monitored at 0,3 , and 6 months. Children with seizures were divided in two groups.

Carbamazepine / Valproic acid was started at $10 \mathrm{mg} /$ $\mathrm{kg} / \mathrm{day}$; the dose was increased depending on clinical response. Patients were followed every 15 days from OPD and were evaluated for drug compliance, adverse 


\section{Original Research Article}

reaction and any sign suggestive of hypothyroidism. Weight, Height, BMI, was monitored at 0 , 3, and 6 months. Fasting venous blood sample for FT3, LFT, KFT were taken under aseptic precaution and tested at baseline and then at 3month and at 6 month interval using RFCL ELISA READER ER 2007 and kit used was ELISCAN (DIAGNOVA) test principal was enzyme immunoassay and recorded in patient Performa. If there was delay in measuring thyroid function sample stored at $-20^{\circ} \mathrm{c}$ in deep freezer. Montoux test CECT head, EEG, CXR, and CSF done accordingly to make diagnosis

Statistical Analysis: Statistical analysis was performed by the SPSS program for Windows, version 17.0. Continuous variables are presented as mean $\pm \mathrm{SD}$, and categorical variables are presented as absolute numbers and percentage.

\section{Results}

This study was carried out in Department of Paediatrics between June 2012 to May 2013. In this prospective study, total 132 children age group of 2-12 years were enrolled in study out of which 98 children were presented with partial/ generalized seizure out of these 98 children, 50 children received carbamazepine, 48 children received valproic acid. 34 children were age and sex matched controls admitted in Department of Paediatrics for diseases other than seizure (e.g. respiratory tract infection, acute gastroenteritis and minor infection) and thyroid function was measured after the resolution of their disease in order to exclude the interference of their pathologies on thyroid function in this group 4 children lost to follow up.

Out of the 50 children in carbamazepine group 1 children developed extensive rash so shifted on valproic acid and excluded from study and 7 children were lost to follow up.

Out of the 48 children in valproic acid group 2 children were diagnosed as tuberculoma and started on ATT and so excluded from final analysis and 6 children were lost to follow up. Finally, 42 children on carbamazepine, 40 children on valproic acid and 30 age sex matched control completed 6 months follow up so comparative data of these children was analysed. All children recruited during the study period were thoroughly examined and were free from any chronic liver/chronic kidney/metabolic disease on clinical grounds. No children received any antiepileptic drug before entering the study. All participants undertook normal daily activities and had nutritionally adequate diets.

Table-1: Group distribution of children

\begin{tabular}{|l|c|c|}
\hline & Frequency & \% \\
\hline Controls & 30 & $26.8 \%$ \\
\hline CBZ & 42 & $37.5 \%$ \\
\hline VPA & 40 & $35.7 \%$ \\
\hline Total & $\mathbf{1 1 2}$ & $\mathbf{1 0 0} \%$ \\
\hline
\end{tabular}

From total 112 analysed children, controls were 30(26.8\%), in carbamazepine group were 42(37.5\%) and in valproic acid group were $40(35.7 \%)$.

Table-2: Age distribution of children.

\begin{tabular}{|l|c|c|c|c|}
\hline Age (years) & $\mathbf{N}$ & Mean \pm SD & Min-Max & P Value \\
\hline Controls & 30 & $6.52 \pm 2.87$ & $2-11$ & 0.621 \\
\hline CBZ & 42 & $6.64 \pm 2.15$ & $2-12$ & \\
\hline VPA & 40 & $7.09 \pm 2.89$ & 2 & \\
\hline
\end{tabular}

Children had mean age of $6.52 \pm 2.87$ in control group, $6.64 \pm 2.15$ in carbamazepine group and $7.09 \pm 2.89$ in valproic acid group which were comparable and there was no significant difference found between control, carbamazepine and valproic acid group $(\mathrm{p}=0.621)$

Pediatric Review: International Journal of Pediatric Research Available online at: www.medresearch.in 462|P a g e 
Table-3: Sex distribution of children.

\begin{tabular}{|c|c|c|c|c|c|}
\hline Sex & Sex & Controls & CBZ & VPA & P Value \\
\hline $\mathrm{F}$ & Frequency & 12 & 18 & 14 & 0.764 \\
\hline & Female & $40.0 \%$ & $42.9 \%$ & $35.0 \%$ & \\
\hline $\mathrm{M}$ & Frequency & 18 & 24 & 26 & \\
\hline Total & Male & $60.0 \%$ & $57.1 \%$ & $65.0 \%$ & \\
\hline
\end{tabular}

Out of 112 children 68 children were male $(60.71 \%)$ and 44 children were female $(39.29 \%)$. In control group ( $\mathrm{n}=30)$, $18(60 \%)$ were male and $12(40 \%)$ were female. In carbamazepine group $(n=42), 24(57.1 \%)$ were male and 18(42.9) were female. And in valproic acid group 26 (65\%) were male and 14 (35\%) were female. All 3 groups in term of sex distribution were comparable and no statistically significant difference was found $(\mathrm{p}=0.764)$.

Table-4: Comparison of mean weight at baseline after 3 months and 6 months in control, carbamazepine and valproic acid group

\begin{tabular}{|c|c|c|c|c|c|}
\hline Weight (kg) & Mean \pm SD & $16.73 \pm 5.00$ & $17.55 \pm 5.35$ & $17.46 \pm 4.81$ & Controls \\
\hline Baseline & Min-Max & $8-25$ & $10-35$ & $8-26$ & P Value \\
\hline & Mean \pm SD & $17.16 \pm 5.16$ & $18.15 \pm 5.23$ & $17.94 \pm 4.86$ & 0.706 \\
\hline 3 Month & Min-Max & $9-25$ & $11-33$ & $9-27$ & 0.654 \\
\hline 6 Month & Mean \pm SD & $17.59 \pm 5.29$ & $18.70 \pm 5.23$ & $18.40 \pm 4.84$ & $10-27$ \\
\hline
\end{tabular}

There was no significant difference $(\mathrm{p}=0.769)$ in mean weight in all groups at baseline. While there was increase in mean weight in all 3 groups but that was not statistically significant at 3 month $(p=0.706)$, and at 6 months ( $p=0.654)$.

Table-5: Comparison of mean height at baseline after 3months and 6 months in control, carbamazepine and valproic acid group

\begin{tabular}{|c|c|c|c|c|c|}
\hline Height (cm) & & $\begin{array}{c}\text { Controls } \\
(\mathbf{n}=\mathbf{3 0})\end{array}$ & $\begin{array}{c}\text { CBZ } \\
(n=42)\end{array}$ & $\begin{array}{c}\text { VPA } \\
(n=40)\end{array}$ & P Value \\
\hline \multirow[t]{2}{*}{ Baseline } & Mean \pm SD & $112.23 \pm 14.23$ & $114.19 \pm 14.53$ & $115.03 \pm 14.52$ & 0.721 \\
\hline & Min-Max & $80-132$ & $86-147$ & $80-147$ & \\
\hline \multirow[t]{2}{*}{3 Month } & Mean \pm SD & $112.62 \pm 13.98$ & $115.11 \pm 14.62$ & $115.46 \pm 14.36$ & 0.682 \\
\hline & Min-Max & $82-133$ & $87-148$ & $82-138$ & \\
\hline \multirow[t]{2}{*}{6 Month } & Mean \pm SD & $113.20 \pm 13.66$ & $116.11 \pm 15.13$ & $116.11 \pm 14.17$ & 0.640 \\
\hline & Min-Max & $83-135$ & $87-152$ & $83-138$ & \\
\hline
\end{tabular}

There was no statistically significant difference $(\mathrm{p}=0.721)$ in mean height in control group $(112.23 \pm 14.23 \mathrm{cms})$, carbamazepine group $(114.19 \pm 14.53 \mathrm{cms})$ and in valproic acid $(115.03 \pm 15.52)$ at baseline. while greatest increase in height is seen in carbamazepine group from $114.19 \pm 14.53 \mathrm{cms}$ to $115.11 \pm 14.62 \mathrm{cms}$ at $3 \mathrm{months}$ and $116.11 \pm 15.13 \mathrm{cms}$ at 6 months but there was no significant difference found between groups at baseline $(\mathrm{p}=0.721)$, at 3 months $(\mathrm{p}=0.682)$, and at 6 months $(\mathrm{P}=0.640)$ after treatment. 
Original Research Article

Table-6: Comparison of ft3 level at baseline after 3 months and 6 months in control carbamazepine and valproic acid group.

\begin{tabular}{|l|c|c|c|c|c|}
\hline FT3 (pmol/l) & & $\begin{array}{c}\text { Controls } \\
(\mathbf{n = 3 0})\end{array}$ & $\begin{array}{c}\text { CBZ } \\
(\mathbf{n = 4 2})\end{array}$ & $\begin{array}{c}\text { VPA } \\
(\mathbf{n = 4 0})\end{array}$ & P Value \\
\hline Baseline & Mean \pm SD & $5.41 \pm 0.92$ & $5.57 \pm 0.90$ & $5.30 \pm 1.06$ & 0.432 \\
\hline 3 Month & Mean \pm SD & $5.28 \pm 0.80$ & $5.51 \pm 0.75$ & $5.31 \pm 0.94$ & 0.434 \\
\hline & Min-Max & $3.9-6.9$ & $3.2-7.1$ & $3.9-8.0$ & \\
\hline 6 Month & Mean \pm SD & $5.30 \pm 34.99$ & $5.13 \pm 0.78$ & $5.41 \pm 0.76$ & 0.372 \\
\hline & Min-Max & $3.8-6.8$ & $3.1-6.8$ & $4.2-7.2$ & \\
\hline
\end{tabular}

No significant difference was found in all 3 groups at baseline $(\mathrm{p}=0.432)$, after 3 months $(\mathrm{p}=0.434)$, and after 6 months $(\mathrm{p}=0.372)$

\section{Discussion}

Current estimates of 50 million people worldwide with epilepsy together with rapid increase in utilization of antiepileptic medications, it is very important to evaluate the side effect of antiepileptic medication on various organ system such as thyroid, it is well known that the traditionally used antiepileptic drugs may affect thyroid functions [6]. The first study about the effect of antiepileptic drugs on thyroid gland was made in 1961 by Oppenheimer et al; they found decrease in iodine bound to serum proteins and a disturbance in thyroxine secretion from thyroxine binding globulin (TBG) in adults taking phenytoin. Since then several studies reported about the toxic effect of antiepileptic drug on thyroid gland [2].

It is found that some antiepileptic drugs decrease thyroid function certainly. For example, phenytoin and carbamazepine clearly decrease the thyroid function but does not change the euthyroid state. It has been reported that these drugs decrease the FT4, but no change in the serum FT3 and TSH level [6]. The present study was a prospective study of 112 children of seizure disorder of varied aetiology in the age group of 2-12 years [Table1] who were started either carbamazepine or valproic acid and FT3 was evaluated at baseline, after 3 months and after 6 months of therapy. In the present study total 112 children were analysed out of which $30(28.8 \%)$ was age and sex matched control, 42 children $(37.5 \%)$ children received carbamazepine and 40 (35.7\%) received valproic acid.

Average age in the present study in control group was $6.52 \pm 2.87$ years, in carbamazepine group $6.64 \pm 2.15$ years and in valproic acid group was $7.09 \pm 2.89$ years. Age of children in all 3 groups was comparable and there was no significant difference found between groups $(\mathrm{p}=0.621)$ [Table-2]. In terms of sex distribution out of 112 children 68 children were male $(60.71 \%)$ and 44 children were female $(39.29 \%)$. In control group $(n=30), 18(60 \%)$ were male and $12(40 \%)$ were female.

In carbamazepine group ( $\mathrm{n}=42), 24(57.1 \%)$ were male and 18 (42.9) were female. And in valproic acid group $26(65 \%)$ were male and $14(35 \%)$ were female. All 3 groups in term of sex distribution were comparable and no statistically significant difference was found $(p=0.764)$ [Table-3]. In term of \pm \pm weight there was no statistically significant difference $(p=0.769)$ at baseline in control group $(16.73 \pm 5.0 \mathrm{~kg})$, carbamazepine group $(17.55 \pm 5.35 \mathrm{~kg})$ and valproic acid group (17.46 \pm 4.81 $\mathrm{kg}$ ), while after 3 months of therapy there was increase in mean weight in all 3 groups but that was not statistically significant $(\mathrm{p}=0.706)$, after 6 months of therapy same increase in mean weight present in all 3 groups that is in control group increase in mean weight from $16.73 \pm 5.00 \mathrm{~kg}$ at baseline to $17.59 \pm 5.29 \mathrm{~kg}$ at 6 months, in carbamazepine group increase in mean weight from $17.59 \pm 5.29 \mathrm{~kg}$ at baseline to $18.40 \pm 4.84 \mathrm{~kg}$ at 6 months, same weight increase was seen in valproic acid group at 6 months but there was no statistically significant difference $(\mathrm{p}=0.654)$ found at 6 months [Table-4].

There was no statistically significant difference $(\mathrm{p}=0.721)$ in mean height in control group $(112.23 \pm 14.23 \mathrm{~cm})$, carbamazepine group $(114.19 \pm 14.53 \mathrm{~cm})$ and in valproic acid $(115.03 \pm 15.52$ $\mathrm{cm})$ at baseline. while greatest increase in height is seen in carbamazepine group from $114.19 \pm 14.53 \mathrm{~cm}$ to $115.11 \pm 14.62 \mathrm{~cm}$ at 3 months and $116.11 \pm 15.13 \mathrm{~cm}$ at 6 


\section{Original Research Article}

months but there was no significant difference found between groups at 3 months $(\mathrm{p}=0.682)$, and at 6 months $(\mathrm{P}=0.640)$ after treatment [Table-5]. In the present study there was no significant difference found in control, CBZ, VPA group at baseline $(\mathrm{p}=0.432)$, after 3 months $(p=0.434)$ and after 6 months $(p=0.37)$ of therapy.

Greatest decrease in mean FT3 level (from 5.57 \pm 0.90 $\mathrm{pmol} / \mathrm{l}$ at baseline, $5.51 \pm 0.75 \mathrm{pmol} / 1$ after 3 months and $5.13 \pm 0.78 \mathrm{pmol} / 1$ after 6 months of therapy) was seen in CBZ group at 6 months even though that was not significant as compared to control and VPA group $(p=0.372)$ [Table -6$]$. These changes are consistent with finding of several studies [7]. Our finding was consistent with study done by A. Verrotti [3] in this study 18 patients received CBZ therapy and 14 patients received VPA therapy and FT3 level were evaluated at baseline, after 3 months, 6 months and after 1 year.

Mean FT3 (pmol/1) remain unchanged at baseline (2.7 \pm 0.9$)$, after 3 months $(2.8 \pm 0.6)$ and after 6 months $(2.7 \pm 0.7)$ of $\mathrm{CBZ}$ therapy and there was no significant difference found in mean FT3 level at 6 months versus control and baseline, same finding was present in VPA group at baseline $(2.7 \pm 0.7)$, after 3 months $(2.7 \pm 0.8)$ and after 6 months $(2.6 \pm 0.8)$ of VPA therapy.

And there was no significant difference found in mean FT3 level at 6 months versus control and baseline. In another study done by Kirimi et al [8], 93 patients were evaluated at baseline, after 3 months and after 6 months of therapy. 23 patients received CBZ. 22 patients received VPA and 50 patients were age and sex matched controls.

This was a cross sectional study in which CBZ group received $\mathrm{CBZ}$ for mean duration of $17.82 \pm 16.11$ months and VPA group received VPA for mean duration of $15.00 \pm 14.88$ months. In this study there was no significant difference found in both CBZ $(3.36 \pm 1.08 \mathrm{pmol} / 1)$ and VPA $(3.53 \pm 0.78 \mathrm{pmol} / 1)$ as compared to control $(3.36 \pm 0.90 \mathrm{pmol} / 1)$. Similar results were found in study done by Leena K. Vainionpaa [9] in 78 girls, 19 girls received CBZ and 41 girls received VPA, FT3 was evaluated after mean duration of therapy of 4.1 years in CBZ group and 3 years of VPA therapy.

In this study FT3 were evaluated and there was no significant difference was found in all 3 groups. Finding of both of these studies are consistent with finding of the present study. While contrast results were found in 2 studies [10, 11]. Talebian Ahmad [10] performed analytical study that was carried out in a cohort fashion without external control, according to this study FT3 level significantly decreased in VPA group $(\mathrm{p}<0.001)$ while there was no significant decrease in FT3 level seen in CBZ group. In contrast, the present study did not find significant difference in both groups. Ali Cansu [11] evaluates the short-term effect of CBZ and VPA monotherapy on thyroid function in children, this study shows significant decrease in FT3 $(\mathrm{pg} / \mathrm{ml})$ in CBZ group $(\mathrm{p}<0.05)$ after 6 months of therapy.

While no significant difference in VPA group. In the present study greatest decrease in mean FT3 level (from $5.57 \pm 0.90 \mathrm{pmol} / 1$ at baseline, $5.51 \pm 0.75 \mathrm{pmol} / 1$ after 3 months and $5.13 \pm 0.78 \mathrm{pmol} / 1$ after 6 months of therapy) was seen in CBZ group at 6 months even though that was not significantly decreased as compared to control or VPA group $(\mathrm{p}=0.372)$.

Mean value of FT3 was not decreased significantly from baseline of $5.57 \pm 0.90 \mathrm{pmol} / 1$ to $5.51 \pm 0.75 \mathrm{pmol} / 1$ at 3 months and $5.30 \pm 0.78$ (Mean \pm SD) after 6 months in patients on CBZ therapy. Mean value of FT3 was not decreased significantly from baseline of $5.30 \pm 1.06$ $\mathrm{pmol} / 1$ to $5.31 \pm 0.94 \mathrm{pmol} / 1$ at 3 months and $5.41 \pm 0.76$ (Mean \pm SD) after 6 months in patients on VPA therapy.

Limitations of the study: In the study the subjects were from the population attending the centre where the study was done and hence it may not be a representative of the general population. The small sample size for proportion for children for various age groups limits its representativeness. A study with more sample size and with better statistical tools needs to be done.

\section{Conclusion}

The present study concluded that the greatest difference decrease in mean FT3 level (from5.57 \pm 0.90 at baseline to $5.13 \pm 0.78 \mathrm{pmol} / 1$ at 6 months in control group though remained unchanged in VPA group, these changes were consistent with the findings of previously conducted studies with few studies reporting contrast results. So, as most of studies suggest that decreased level of FT3 seen in patients on long term monotherapy of CBZ but they remained euthyroid, but these changes are reversible.

\section{What this study adds to existing knowledge?}

This study revealed that after 6 months of therapy with carbamazepine no significant decrease in FT3 found in both carbamazepine and valproic acid group after 6 


\section{Original Research Article}

months of therapy. So, six monthly thyroid profile may be an option to see the changes in FT3 levels on long term CBZ therapy ( $>6$ months).

\section{Author's contribution}

Dr. Dharmender Gupta: Statistical analysis of data, manuscript preparation, editing, and review and final approval of the version to be submitted.

Dr. Atul Kumar: The concept and design of the study, acquisition of data, search of literature and interpretation of data

Funding: Nil, Conflict of interest: None initiated, Permission from IRB: Yes

\section{References}

1. Johnston MV. Seizures in childhood. In: Kliegman RM, Jenson HB, Behrman RE, Stanton BF, editors. Nelson textbook of pediatrics. $18^{\text {th }}$ Ed. New Delhi: Elsevier; 2008. p. 2457-78.

2.Oppenheimer JH, Fisher LV, Nelson KM, Jailer JW. Depression of the serum protein-bound iodine level by diphenylhydantoin. J Clin Endocrinol Metab. 1961;2: 252-262. doi: https://doi.org/10.1210/jcem-21-3-252.

3. Verrotti A, LANs M, Scardapane A, Franzomi E, Chiarelli F. 'Thyroid hormone in children during long term administration of Carbamazepine and Valproate'. Europe J Endocrinol. 2009;160(1):81-86. doi: 10.1530/ EJE- 08-0325.

4.Connacher AA, Borsey DQ, Browning MCK, Davidson DLW, Jung RT. The effective evaluation of thyroid status in patient on Phenytoin, Carbamazepine or Sodium Valproate attending an epilepsy clinic. Pg Med J. 1987; 63(744):841-845. doi: 10.1136/pgmj.63. 744.841
5. Eris-Punal J, Del Rio-Garma M, Del Rio-Garma MC, Lojo-Rocamonde S, Novo-Rodriguez I, Castro-Gago M. Long-term treatment of children with epilepsy with valproate or carbamazepine may cause subclinical hypothyroidism. Epilepsia. 1999; 40 (12): 1761-1766. doi:https://doi.org/10.1111/j.1528-1157.1999.tb01595.x

6. Bentsen K.D., Gram L and Veje A. 'Serum thyroid hormone and blood folic acid during monotherapy with Carbamazepine, and Valproic acid' Acta Neurol. Scand. 1983; 67 (4): 235-241. doi: https://doi.org/10.1111/j. 1600-0404. 1983. tb04569.x

7. Haidukewych D, Rodin EA. Chronic epileptic drug therapy. Classification by medication regimen and incidence of decrease in serum thyroxin and free thyroxin index. The Drug Monit 1987;9(4):392-398.

8. Kirimie, Karasali Hoglu S, Boz A, 'Thyroid functions in children under long term administration of antiepileptic drugs'. Eastern J Med. 1999; 4(1):23-26

9. Vainionpää LK, Mikkonen K, Rättyä J, Knip M, Pakarinen AJ, Myllylä VV, et al. Thyroid function in girls with epilepsy with Carbamazepine, oxcarbamazepine or Valproate monotherapy and after withdrawal of medication' Epilepsia. 2003; 45(3):197-199.doi: https:// doi.org/10.1111/j.0013-9580.2004.26003.x

10.Ahmad T, Es Lalmian, Raza M, Kobra S, Abedi MM, Raza A. Changing in thyroid function test in children underwent antiepileptic therapy' Iran J. Child Neurol. 2010;4(1).

11. Cansu A, Serdaroglu A, Camurdan O, Hirfanoglu T, Bideci A, Gucuyener K. The evaluation of thyroid function, thyroid antibodies and thyroid volumes in children with epilepsy during short term administration of oxcarbazepine and valproate. Epilepsia. 2007;47: 1855-1859.

\section{How to cite this article?}

Gupta D, Kumar A. Comparative study of carbamazepine and sodium valproate on - free triiodothyronine, in paediatric patients in teaching hospital. Int J Pediatr Res.2019;6(09):460-466.doi:10.17511/ijpr.2019.i09.04

Pediatric Review: International Journal of Pediatric Research Available online at: www.medresearch.in 466|P a g e 